\title{
Effect of Renal Impairment on the Pharmacokinetics of Disopyramide and Its Metabolite and Serum Insulin Level : A Single Dose Study
}

\author{
Kazuhiro HARADA ${ }^{* 1, * 2}$ Tomoko HASUNUMA ${ }^{* 1, * 3}$ Tsutomu KOTEGAWA ${ }^{* 1, * 4}$ \\ Eiji UCHIDA $^{* 1, * 5}$ Tomonori TATEISHI ${ }^{* 1, * 6}$ Takehiko KAWANISHI ${ }^{* 7}$ \\ and ANTCliPh Trial 01 Study Group*1 \\ *1 Academic Network for Trials in Clinical Pharmacology (ANTCliPh) \\ *2 Department of Internal Medicine, Kasaoka Daiichi Hospital, Okayama, Japan \\ ${ }^{* 3}$ Kitasato University Research Center for Clinical Pharmacology, Tokyo, Japan \\ *4 Department of Clinical Pharmacology and Therapeutics, Oita University Faculty of Medicine, Oita, Japan \\ *5 Second Department of Pharmacology, Showa University School of Medicine, Tokyo, Japan \\ ${ }^{* 6}$ Department of Clinical Pharmacology, Hirosaki University Graduate School of Medicine, Aomori, Japan \\ ${ }^{* 7}$ Clinical Pharmacology Department, Chugai Clinical Co., LTD, Tokyo, Japan \\ ANTCliPh Trial 01 Study Group as coauthor (place: member in alphabetical order) \\ - Kasaoka Daiichi Hospital : Toshihiro Honda, Junichi Nakamura \\ - Kitasato University Research Center for Clinical Pharmacology : Megumi Hashimoto, Yutaka Hashizume, \\ Sakiko Inamoto, Teruo Inamoto, Satoshi Makino, Tomoko Matsumura, Masahiko Nakamura, Shinichiro Nishio, \\ Kei Ohnuma, Masaru Takasu, Yuji Tanaka, Hiroshi Yamashita, Koji You, Koichiro Yuji \\ - Nippon Medical School Hospital : Yasuhiko Iino, Tomohiro Kaneko, Koichi Utsumi \\ - Oita University Hospital : Hiromitsu Imai, Takuya Morimoto, Kyoichi Ohashi, Toshiaki Okudaira, Fuminori \\ Sato, Naohiko Takahashi
}

\begin{abstract}
Preexisting chronic renal failure is a major risk factor of disopyramide-induced hypoglycemia because renal excretion plays a major role in the elimination of disopyramide from systemic circulation. We evaluated the effect of renal failure on the pharmacokinetics of disopyramide, and examined the relationship between plasma disopyramide concentration and serum level of glucose or insulin.

Seventeen subjects with mild to severe chronic renal impairment estimated by the Cockcroft-Gault method and without arrhythmia were enrolled and administered a single oral dose of $100 \mathrm{mg}$ disopyramide after overnight fasting. Four and 24-hour creatinine clearance correlated significantly with AUC $(\mathrm{r}=0.620$ and 0.554 for 4-hour and 24-hour methods, respectively), CL/F ( $\mathrm{r}=0.553$ and 0.520$)$ and $\mathrm{t}_{1 / 2}(\mathrm{r}=0.584$ and 0.616$)$ of disopyramide, as well as AUC $(\mathrm{r}=0.625$ and 0.532$)$ and $\mathrm{t}_{1 / 2}(\mathrm{r}=0.611$ and 0.670$)$ of monoisopropyl disopyramide, the major metabolite, but did not correlate with $\mathrm{C}_{\max }$ of disopyramide or its metabolite. Serum concentration of alpha-1 acid glycoprotein (AAG) correlated significantly with the pharmacokinetic parameters of disopyramide. Both serum glucose and insulin levels decreased significantly 4 hours after disopyramide administration compared to before dosing, and a weak but significant correlation was observed between plasma disopyramide concentration and the change in serum insulin level $(r=0.373)$, but not the change in serum glucose level.

In conclusion, disopyramide pharmacokinetics is affected not only by renal function impairment, but also by serum AAG concentration. In addition to severe renal function impairment, higher serum AAG concentration may be a risk factor that elevates plasma disopyramide concentration and induces toxic effects.
\end{abstract}

Key words : chronic renal failure, disopyramide, pharmacokinetic, alpha-1 acid glycoprotein, monoisopropyl disopyramide

\section{Introduction}

Disopyramide, a class 1A antiarrhythmic drug, has electrophysiological effects very similar to those of quinidine and procainamide, and is used to maintain normal sinus rhythm in patients with atrial flutter or fibrillation or to reduce the frequency of premature ventricular contractions and prevent ventricular

Address for correspondence : IIJIMA H. Kitasato University Research Center for Clinical Pharmacology, 5-9-1 Shirokane, Minato-ku, Tokyo 108-8642, Japan

(Manuscript received March 18, 2009 ; revised July 16, 2009 and September 7, 2009 ; accepted September 14, 2009) 
tachycardia ${ }^{1)}$. Disopyramide is mainly eliminated into the urine. At 24 hours after oral administration, 40$50 \%$ of the single dose administered were excreted into the urine in the form of $75 \%$ disopyramide and $25 \%$ a major metabolite, monoisopropyldisopyramide in healthy subjects ${ }^{2}$. Therefore, the adjustment of dosage is recommended in patients with renal failure $^{2,3)}$ in order to prevent a rise in plasma concentrations leading to adverse reactions of disopyramide such as excessive QT interval prolongation of the ECG, negative inotropic effect, and anticholinergic effect ${ }^{1)}$. In addition to those undesirable effects, hypoglycemia has been reported to develop following the treatment with disopyramide ${ }^{4,5)}$.

Cacoub et al. presented their own case and a review of previous case reports, and suggested that preexisting chronic renal failure is a major risk factor of disopyramide-induced hypoglycemia ${ }^{6}$. It has been reported that disopyramide is bound to alpha-1 acid glycoprotein (AAG) in plasma and the serum concentrations of this protein were higher in uremic patients than in the healthy control subjects ${ }^{7.8)}$. In patients with renal function impairment, elevated serum AAG concentration might affect the pharmacokinetics of disopyramide, contributing to the development of disopyramide-induced hypoglycemia.

In this study, therefore, we evaluated the effect of renal failure on the pharmacokinetics of disopyramide after a single oral administration, and examined the relationship between plasma disopyramide concentration and serum level of glucose or insulin because disopyramide pharmacokinetics is affected by chronic renal function impairment might contribute to developing hypoglycemia. We also measured serum AAG concentrations in our subjects to examine the effect of renal function impairment on serum AAG concentrations and also studied whether disopyramide pharmacokinetics was related with serum AAG concentration.

\section{Methods}

\section{Subjects}

Seventeen subjects ( 8 males and 9 females) with stable chronic renal impairment (CLcr calculated by the Cockcroft-Gault method ${ }^{9)}$ ranging between 26 and $76 \mathrm{~mL} / \mathrm{min}$ ) participated in this study. Mean age, height, and bodyweight were 68.8 y. o (58 to 75 y. o), $157.3 \mathrm{~cm}$ ( 140.5 to $179.7 \mathrm{~cm}$ ), and $63.5 \mathrm{~kg}$ ( 45.6 to $84.2 \mathrm{~kg})$ respectively. The inclusion criteria were as follows ; 1) subjects aged between 20 and 75 y. o, 2) values of creatinine clearance (CLcr) estimated by the Cockcroft-Gault method ranging between 10 and $80 \mathrm{~mL} / \mathrm{min}$. Subjects were ineligible if they were on hemodialysis or peritoneal dialysis treatment or if they had atrioventricular conduction disturbances ; any heart disease causing heart failure; diabetes mellitus with $\mathrm{HbAlc}$ being more than $8.0 \%$; anemia with hemoglobin being less than $10 \mathrm{~g} / \mathrm{dL}$; hypoproteinemia (less than $6.0 \mathrm{~g} / \mathrm{dL}$ ) and/or hypoalbuminemia (less than $3.0 \mathrm{~g} / \mathrm{dL}$ ) ; abnormal liver function showing 2.5-fold or more the upper limit of normal, or they were treated with antiarrhythmic drugs ; medication induced QT prolongation on ECG ; medication affected the CYP3A4 activity in vivo. Subjects were also excluded if they were on hemodialysis or peritoneal dialysis treatment or judged as unsuitable to participate in the study by the investigators. All subjects gave written informed consent prior to the initiation of any trial procedures, and the study was conducted in Kitasato Institute Hospital $(n=8)$, Kasaoka Daiichi Hospital $(\mathrm{n}=6)$, and Oita University Hospital $(n=3)$. The institutional review board at each site approved the study protocol.

Participants were allowed to take medications, except a $\beta$-blocker that blocks glycogenolysis and impair perception of the symptoms of hypoglycemia ${ }^{10)}$, without the change in dosage, if these medications were administered before the study, during the study period. They were required to abstain from ingestion of alcohol and grapefruit juice during hospitalization, and also refrain from smoking until the lunch at the day when disopyramide was administered.

\section{Study design}

After giving written informed consent, participants were screened by their medical history and clinical, haematological and biochemical findings. The screening was carried out between 5 to 21 days before disopyramide administration, and subjects were categorized into mild, moderate and severe renal insufficiency according to their CLcr level obtained by the Cockcroft-Gault method. Definition used for mild, moderate, and severe renal function impairment was a CLcr level comprised between 50 and $80(\mathrm{~mL} / \mathrm{min})$, 30 and $50(\mathrm{~mL} / \mathrm{min})$, and 10 and $30(\mathrm{~mL} / \mathrm{min})$ respectively. They were hospitalized between 1 day before and 3 days after the administration of disopyramide. At the day of the hospitalization, 4hour CLcr was evaluated. At the day of the 
administration, participants were administered one capsule of $100 \mathrm{mg}$ disopyramide at $8 \mathrm{AM}$ after overnight fasting. They were required to keep a sitting or standing position and fasting until 4 hours after the administration.

Venous blood samples were taken before and at 1 , $2,3,4,6,8,12,24$, and 48 hours for determination of the concentrations of disopyramide and its major metabolite, monoisopropyldisopyramide, and urine samples were collected between 0 and 24 , and 24 and 48 to evaluate 24-hour CLcr after the administration of disopyramide. Unbound concentrations of disopyramide and monoisopropyldisopyramide in serum were determined at 3 and 12 hours after the administration. Serum AAG concentration was determined in the blood sample taken just before the administration. Serum level of glucose and insulin were determined before and at 1,2, and 4 hours after the administration, and fasting serum glucose level was also determined at 24 and 48 hours. More than 15\% decrease in serum glucose level after disopyramide administration from the level before the administration was regarded as drug-induced decrease in serum glucose level. Sitting blood pressure and pulse rate monitoring and 12-lead ECG recording were performed before and at 3, 6, 12, 24, 48 hours after the administration. A post-trial medical examination, with measurement of vital signs, routine laboratory safety tests and 12-lead ECG was also performed between 6 and 10 days after the administration.

Adverse events were assessed by spontaneous reports and investigator observation throughout the study. The onset and intensity (serious, non serious) of adverse events after drug administration were reported as part of the investigator assessment of possible causality.

\section{Determination of disopyramide and monoiso- propyldisopyramide}

Serum and serum ultrafiltrate concentrations of disopyramide and monoisopropyldisopyramide were analyzed at Mitsubishi Kagaku Bio-Clinical Laboratories (Tokyo, Japan) by a liquid chromatographytandem mass spectrometry (LC/MS/MS) method with parachlorodisopyramide as the internal standard. In brief, $25 \mu \mathrm{L}$ of methanol, $500 \mu \mathrm{L}$ of sodium hydroxide solution and $5 \mathrm{~mL}$ of tert-butyl methyl ether were added to $50 \mu \mathrm{L}$ samples. After mixing and centrifugation, the water layer was frozen in dry-iced methanol and the organic layer was collected and evaporated under the flow of nitrogen gas. The residue of the organic layer was reconstituted with $2 \mathrm{~mL}$ of the mobile phase (methanol/water/formic acid, $600: 400: 1$ ) and $5 \mu \mathrm{L}$ was injected into Capcell Pak C18 AQ $5 \mu \mathrm{M}$ column (Shiseido, Tokyo, Japan) coupled to an HPLC system (Waters, Milford, USA). Detection was performed by MS/MS with electrospray ionization (ESI) using a Finnigan TSQ 7000 (Thermo Electron, Waltham, USA) mass spectrometer. The masses for disopyramide and monoisopropyldisopyramide were precursor ion $\mathrm{m} / \mathrm{z} 340.0$ and $\mathrm{m} / \mathrm{z}$ 297.9, and product ion $\mathrm{m} / \mathrm{z} 239.1$ and 239.1, respectively. The masses for parachlorodisopyramide were precursor ion $\mathrm{m} / \mathrm{z} 374.0$ and product ion $\mathrm{m} / \mathrm{z}$ 273.1. A standard curve used before the analysis ranged from 10 to $2000 \mathrm{ng} / \mathrm{mL}$ for disopyramide and from 10 to $1000 \mathrm{ng} / \mathrm{mL}$ for monoisopropyldisopyramide. The lower limit of quantification for both analytes was $10 \mathrm{ng} / \mathrm{mL}$. The interassay accuracy for disopyramide at nominal concentrations of 10, 30, 150, and $1600 \mathrm{ng} / \mathrm{mL}$ ranged from $3.4 \%$ to $6.6 \%$ and the interassay precision ranged from $4.2 \%$ to $9.9 \%$. The interassay accuracy for monoisopropyldisopyramide at nominal concentrations of 10,30,150, and $800 \mathrm{ng} /$ $\mathrm{mL}$ ranged from -5.3 to $2.0 \%$ and the interassay precision ranged from 3.1 to $11.8 \%$.

\section{Pharmacokinetic data analysis}

The peak plasma drug concentration $\left(\mathrm{C}_{\max }\right)$ and the time to $\mathrm{C}_{\max }\left(\mathrm{T}_{\max }\right)$ were obtained from direct observation of the data. The terminal elimination rate constant $\left(\mathrm{k}_{\mathrm{el}}\right)$ was calculated by log-linear regression of the terminal portion of the concentration-time profile and the elimination half-life $\left(\mathrm{t}_{1 / 2}\right)$ was obtained by $0.693 / \mathrm{k}_{\text {el }}$. The area under the plasma concentration-time curve from time zero to $48 \mathrm{~h}$ $\left(\mathrm{AUC}_{0 \rightarrow 48 \mathrm{~h}}\right)$ was calculated by the linear trapezoidal method from 0 hour to 48 hours, and extrapolated to infinity using $\mathrm{k}_{\mathrm{el}}$ to obtain $\mathrm{AUC}_{0 \rightarrow \infty}$. The apparent oral clearance $(\mathrm{CL} / \mathrm{F})$ was obtained from the equation $\mathrm{CL} /$ $\mathrm{F}=$ Dose $/ \mathrm{AUC}_{0 \rightarrow \infty}$, and the apparent volume of distribution $(\mathrm{Vd} / \mathrm{F})$ was obtained from the equation $\mathrm{Vd} / \mathrm{F}=\mathrm{CL} / \mathrm{F} / \mathrm{k}_{\mathrm{el}}$ (WinNonlin 4.1, Pharsight Co., NC, USA).

The unbound fraction of disopyramide or monoisopropyldisopyramide was obtained by the ultrafiltration method using Centrifree UF Device with YM-T membrane (Cat. \#4104, Millipore Co., San Francisco, 
Table 1 The demographic profiles of subjects who were categorized into mild, moderate and severe renal insufficiency

\begin{tabular}{|c|c|c|c|c|c|c|c|c|}
\hline $\begin{array}{c}\text { Renal } \\
\text { insufficiency }\end{array}$ & $\mathrm{N}(\mathrm{M} / \mathrm{F})$ & Age (у. о.) & Height $(\mathrm{cm})$ & BW（kg） & $\begin{array}{l}\text { CLcr by CG } \\
(\mathrm{mL} / \mathrm{min})\end{array}$ & $\begin{array}{l}\text { CLcr by } 4 \text {-hour } \\
(\mathrm{mL} / \mathrm{min})\end{array}$ & $\begin{array}{l}\text { CLcr by } 24 \text {-hour } \\
(\mathrm{mL} / \mathrm{min})\end{array}$ & $\begin{array}{c}\mathrm{AAG} \\
(\mathrm{mg} / \mathrm{dL})\end{array}$ \\
\hline mild & $6(1 / 5)$ & $67.0 \pm 7.0$ & $155.3 \pm 13.3$ & $61.5 \pm 14.6$ & $65.8 \pm 7.4$ & $95.6 \pm 25.8$ & $89.4 \pm 23.2$ & $73.7 \pm 16.4$ \\
\hline moderate & $7(6 / 1)$ & $69.4 \pm 3.2$ & $160.8 \pm 6.4$ & $67.7 \pm 8.3$ & $43.6 \pm 5.7$ & $73.5 \pm 18.8$ & $62.8 \pm 14.0$ & $75.4 \pm 22.2$ \\
\hline severe & $4(1 / 3)$ & $70.5 \pm 4.5$ & $154.1 \pm 7.0$ & $59.2 \pm 6.1$ & $27.0 \pm 0.8$ & $42.6 \pm 13.0$ & $32.7 \pm 10.4$ & $80.1 \pm 25.5$ \\
\hline total & $17(8 / 9)$ & $68.8 \pm 5.0$ & $157.3 \pm 9.4$ & $63.5 \pm 10.7$ & $47.51 \pm 6.3$ & $74.0 \pm 28.2$ & $65.1 \pm 27.3$ & $75.9 \pm 19.9$ \\
\hline
\end{tabular}

mild : renal function impairment group defined between 50 and $80(\mathrm{~mL} / \mathrm{min})$ in CLcr level obtained by the Cockcroft-Gault method, moderate : renal function impairment group defined between 30 and $50(\mathrm{~mL} / \mathrm{min})$ in CLcr level obtained by the Cockcroft-Gault method, severe : renal function impairment group defined between 10 and $30(\mathrm{~mL} / \mathrm{min})$ in CLcr level obtained by the Cockcroft-Gault method, CG : the Cockcroft-Gault method, CLcr : creatinine clearance, AAG : alpha-1 acid glycoprotein

CA, USA), and the bound fraction was obtained by the following equation: (total drug concentrationunbound drug concentration) divided by total drug concentration. When the unbound drug concentration was greater than the total drug concentration, which was found in monoisopropyldisopyramide but not in disopyramide, the bound fraction was regarded as 0 . The relationship between the serum total concentration of disopyramide or monoisopropyldisopyramide and its binding ability was analyzed by a Scatchard analysis, and the binding parameters were obtained by fitting the following equation to the data $: \mathrm{Cb}=(\mathrm{Nb}$ $\times \mathrm{P} \times \mathrm{Cf}) /(\mathrm{Kd}+\mathrm{Cf})$, where $\mathrm{Cb}$ is the bound drug concentration, $\mathrm{Nb}$ is the number of binding sites per molecular of AAG, $\mathrm{P}$ is the serum concentration of $\mathrm{AAG}, \mathrm{Kd}$ is the dissociation constant for a specific binding site, and $\mathrm{Cf}$ is the unbound drug concentration $^{11)}$. The number of binding sites and the dissociation constant for a specific binding site were estimated by the nonlinear least-square method (Splus 7.0J, Insight Corporation, WA, USA).

\section{Statistical analysis}

Data are presented as the mean \pm standard deviation (SD). Linear correlation was calculated by a least square method. Repeated-measures ANOVA was used for statistical differences in the mean serum level of glucose and insulin between before and after the disopyramide administration. The $\mathrm{p}$ value $<.05$ was considered statistically significant.

\section{Results}

All 17 subjects entered and completed the study and their baseline demographics are described in Table 1 . The numbers of subjects with mild, moderate, and severe renal function impairment were 6,7 , and 4 , respectively. There was one protocol violation in which plasma Ca concentrations before and at 48 hours after the disopyramide administration were not measured in one subject with moderate renal function impairment, but all participants were included in the analyses of pharmacokinetic parameters and safety.

\section{Pharmacokinetic findings}

Disopyramide and monoisopropyldisopyramide plasma concentration-time profiles are shown in Fig. 1, and their pharmacokinetic parameters are summarized in correlated with their renal functions (Table 2). Disopyramide $t_{1 / 2}$ was significantly correlated with any of the CLcr values obtained by the CockcroftGault method $\left(\mathrm{t}_{1 / 2}=-0.11 \times \mathrm{CLcr}+16.73, \mathrm{n}=17, \mathrm{r}=\right.$ $0.501, \mathrm{p}=0.0407)$, 4-hour method $\left(\mathrm{t}_{1 / 2}=-0.073 \times\right.$ CLcr $+17.08, n=17, r=0.584, p=0.0139)$, or 24-hour method $\left(\mathrm{t}_{1 / 2}=-0.079 \times \mathrm{CLcr}+16.84, \mathrm{n}=17, \mathrm{r}=0.616\right.$, $\mathrm{p}=0.0085$, Fig. 2). Other pharmacokinetic parameters including the AUC (4-hour method, $\mathrm{AUC}=-$ $290.4 \times$ CLcr $+46831, \mathrm{n}=17, \mathrm{r}=0.620, \mathrm{p}=0.0080: 24$ hour method, $\mathrm{AUC}=-267.6 \times \mathrm{CLcr}+42749, \mathrm{n}=17$, $\mathrm{r}=0.554, \mathrm{p}=0.0209)$ and $\mathrm{CL} / \mathrm{F}$ (4-hour method, CL/ $\mathrm{F}=34.48 \times \mathrm{CLcr}+2165.3, \quad \mathrm{n}=17, \quad \mathrm{r}=0.553, \quad \mathrm{p}=$ 0.0214:24-hour method, CL/F $=33.38 \times \mathrm{CLcr}+$ 2544.7, $\mathrm{n}=17, \mathrm{r}=0.520, \mathrm{p}=0.0324)$ of disopyramide and the AUC (4-hour method, $\mathrm{AUC}=-41.58 \times$ CLcr $+7225.1, \mathrm{n}=17, \mathrm{r}=0.625, \mathrm{p}=0.0073: 24$-hour method, $\mathrm{AUC}=-36.47 \times \mathrm{CLcr}+6521.1, \mathrm{n}=17, \mathrm{r}=$ $0.532, \mathrm{p}=0.0278$ ) and $\mathrm{t}_{1 / 2}$ (4-hour method, $\mathrm{t}_{1 / 2}=-$ $0.088 \times \mathrm{CLcr}+21.132, \mathrm{n}=17, \mathrm{r}=0.611, \mathrm{p}=0.0092$ : 24-hour method, $\mathrm{t}_{1 / 2}=-0.099 \times \mathrm{CLcr}+21.088, \mathrm{n}=17$, $\mathrm{r}=0.670, \mathrm{p}=0.0033)$ of monoisopropyldisopyramide were significantly correlated with CLcr of 4- and 24hour methods, whereas $\mathrm{C}_{\max }$ of disopyramide or its metabolite was not.

Mean serum concentration $( \pm \mathrm{SD})$ of $\mathrm{AAG}$ was $75.9 \pm 19.9 \mathrm{mg} / \mathrm{dL}$, but there was no difference in its 


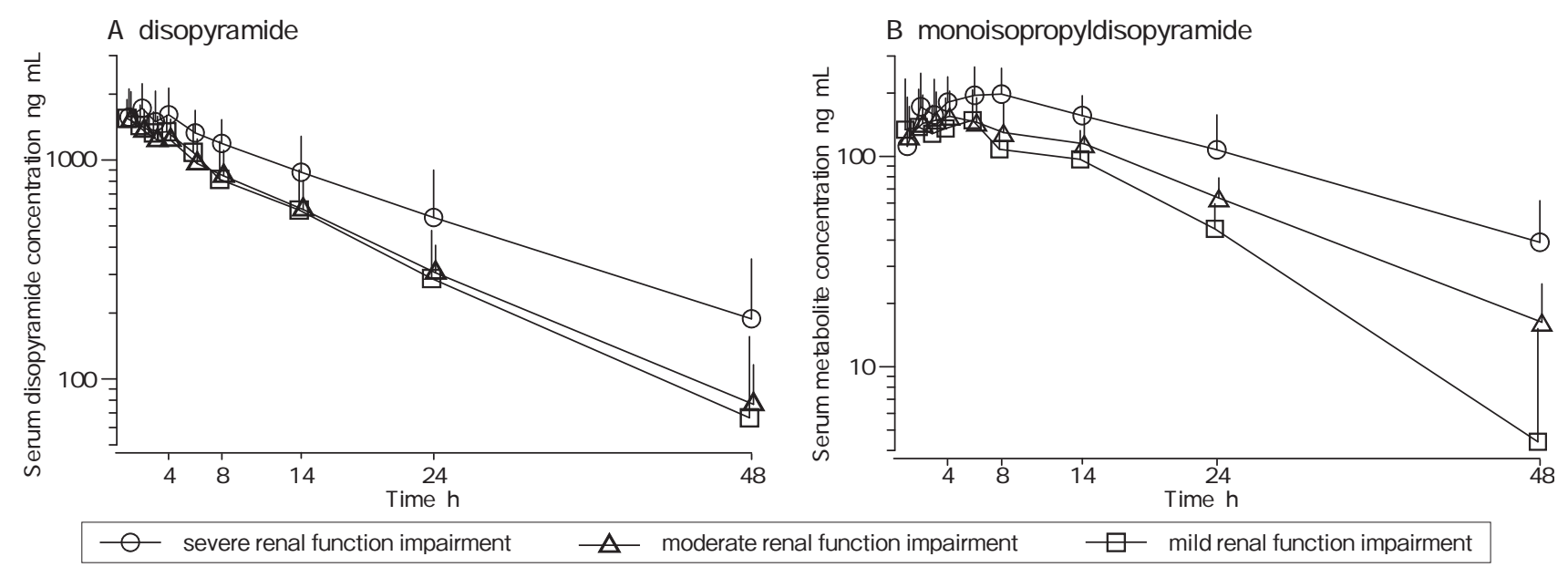

Fig. 1 Mean serum concentration vs. time profiles of (A) disopyramide and (B) its major metabolite, monoisopropyldisopyramide, after a single oral dose of $100 \mathrm{mg}$ disopyramide in each group of renal function impairment

Table 2 The pharmacokinetic parameters of disopyramide and its major metabolite, monoisopropyldisopyramide, in each group of renal function impairment

\begin{tabular}{c|c|c|c|c|c|c|c|c|c|c|c}
\hline \multicolumn{2}{c|}{} & \multicolumn{2}{c|}{$\mathrm{T}_{\max }(\mathrm{h})$} & \multicolumn{2}{c|}{$\mathrm{C}_{\max }(\mathrm{ng} / \mathrm{mL})$} & \multicolumn{2}{|c|}{$\mathrm{AUC}_{0 \rightarrow \infty}(\mathrm{ng} \cdot \mathrm{h} / \mathrm{mL})$} & $\mathrm{CL} / \mathrm{F}(\mathrm{mL} / \mathrm{min})$ & \multicolumn{2}{c|}{$\mathrm{t}_{1 / 2}(\mathrm{~h})$} & $\mathrm{Vd} / \mathrm{F}(\mathrm{L})$ \\
\hline \multirow{2}{*}{ mild } & $\begin{array}{c}\mathrm{N} \\
\mathrm{M} / \mathrm{F})\end{array}$ & $\mathrm{D}$ & $\mathrm{Met}$ & $\mathrm{D}$ & $\mathrm{Met}$ & $\mathrm{D}$ & $\mathrm{Met}$ & $\mathrm{D}$ & $\mathrm{D}$ & $\mathrm{Met}$ & $\mathrm{D}$ \\
& $\begin{array}{c}6 \\
(1 / 5)\end{array}$ & $\begin{array}{c}1.5 \\
\pm 0.5\end{array}$ & $\begin{array}{c}3.7 \\
\pm 2.1\end{array}$ & $\begin{array}{c}1690 \\
\pm 353\end{array}$ & $\begin{array}{c}185 \\
\pm 77\end{array}$ & $\begin{array}{c}21942 \\
\pm 11439\end{array}$ & $\begin{array}{c}3070 \\
\pm 834\end{array}$ & $\begin{array}{c}5263 \\
\pm 1683\end{array}$ & $\begin{array}{c}9.95 \\
\pm 2.98\end{array}$ & $\begin{array}{c}12.56 \\
\pm 2.82\end{array}$ & $\begin{array}{c}69.7 \\
\pm 12.0\end{array}$ \\
\hline \multirow{2}{*}{ moderate } & 7 & 1.9 & 4.3 & 1567 & 165 & 21953 & 3829 & 4987 & 11.57 & 14.44 & 79.8 \\
& $(6 / 1)$ & \pm 1.5 & \pm 2.1 & \pm 488 & \pm 47 & \pm 6840 & \pm 946 & \pm 1691 & \pm 2.19 & \pm 2.76 & \pm 16.4 \\
\hline \multirow{2}{*}{ severe } & 4 & 2.5 & 6.5 & 1749 & 202 & 36329 & 6318 & 3428 & 14.47 & 18.12 & 63.0 \\
& $(1 / 3)$ & \pm 1.0 & \pm 1.0 & \pm 489 & \pm 69 & \pm 20160 & \pm 2632 & \pm 1737 & \pm 5.02 & \pm 5.81 & \pm 16.6 \\
\hline
\end{tabular}

D : disopyramide. Met : monoisopropyldisopyramide,

mild : renal function impairment group defined between 50 and $80(\mathrm{~mL} / \mathrm{min})$ in creatinine clearance (CLcr) level obtained by the Cockcroft-Gault method,

moderate : renal function impairment group defined between 30 and $50(\mathrm{~mL} / \mathrm{min})$ in CLcr level obtained by the Cockcroft-Gault method, severe : renal function impairment group defined between 10 and $30(\mathrm{~mL} / \mathrm{min})$ in CLcr level obtained by the Cockcroft-Gault method, $\mathrm{AUC}_{0 \rightarrow \infty}$ : area under the concentration curve from zero to infinity $(\mathrm{ng} \cdot \mathrm{h} / \mathrm{mL}), \mathrm{CL} / \mathrm{F}:$ apparent oral clearance, $\mathrm{t}_{1 / 2}:$ elimination half-life, $\mathrm{C}_{\max }$ : maximum plasma concentration, $\mathrm{t}_{\max }$ : time to $\mathrm{C}_{\max }(\mathrm{h}), \mathrm{Vd} / \mathrm{F}:$ apparent volume of distribution.

concentration between the three groups with different renal function impairment (Table 1). The serum concentration of AAG correlated significantly with $\mathrm{t}_{1 / 2}$ $\left(\mathrm{t}_{1 / 2}=0.109 \times \mathrm{AAG}+3.380, \quad \mathrm{n}=17, \quad \mathrm{r}=0.620, \quad \mathrm{p}=\right.$ 0.0080, Fig. 3), AUC (AUC $=503.3 \times A A G-12870, n$ $=17, \mathrm{r}=0.760, \mathrm{p}=0.0004), \mathrm{CL} / \mathrm{F}(\mathrm{CL} / \mathrm{F}=-61.77 \times$ $\mathrm{AAG}+9406, \mathrm{n}=17, \mathrm{r}=0.701, \mathrm{p}=0.0017)$, and $\mathrm{Vd} / \mathrm{F}$ $(\mathrm{Vd} / \mathrm{F}=-0.518 \times \mathrm{AAG}+111.6, \mathrm{n}=17, \mathrm{r}=0.658, \mathrm{p}=$ 0.0041 ) of disopyramide, but not with those of monoisopropyldisopyramide. Mean levels $( \pm$ SD) of bound fraction (\%) at 3 and 12 hours after the administration were $65.7 \pm 10.3$ and $72.0 \pm 7.6$ for disopyramide, respectively, and $8.4 \pm 8.1$ and $12.3 \pm$ 9.7 for monoisopropyldisopyramide, respectively. In the binding parameters of disopyramide, the number of binding site $(\mathrm{Nb})$ and the dissociation constant for a specific binding site $(\mathrm{Kd})$ were estimated as 0.24 and $0.838 \mu \mathrm{M}$, respectively.

\section{The serum concentrations of glucose, insulin, and disopyramide and its metabolite}

Among the 17 subjects in our present study, five subjects were treated with sulfonylurea or insulin. We, therefore, evaluated serum level of glucose and insulin in the 12 subjects without those treatments. Between before and at 4 hours after the disopyramide administration, serum glucose level before the disopyramide administration was $98.2 \pm 9.0 \mathrm{mg} / \mathrm{dL}$ $(103.6 \pm 7.1 / 95.4 \pm 9.7 / 96$ and 87 [mild $(n=5) /$ moderate $(n=5) /$ severe $(n=2)])$, which signifi- 


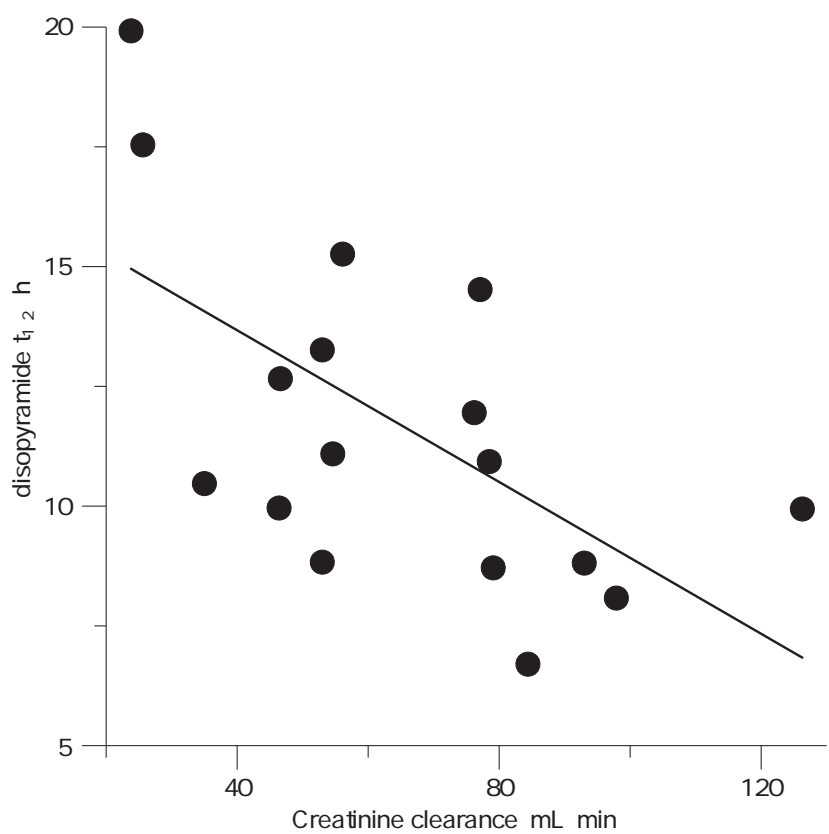

Fig. 2 Relation of the elimination half-life of disopyramide and the creatinine clearance (CLcr) obtained by the 24-hour method $\left(t_{1 / 2}=-0.079\right.$ $\times$ CLcr $+16.84, n=17, r=0.616, p=0.0085)$

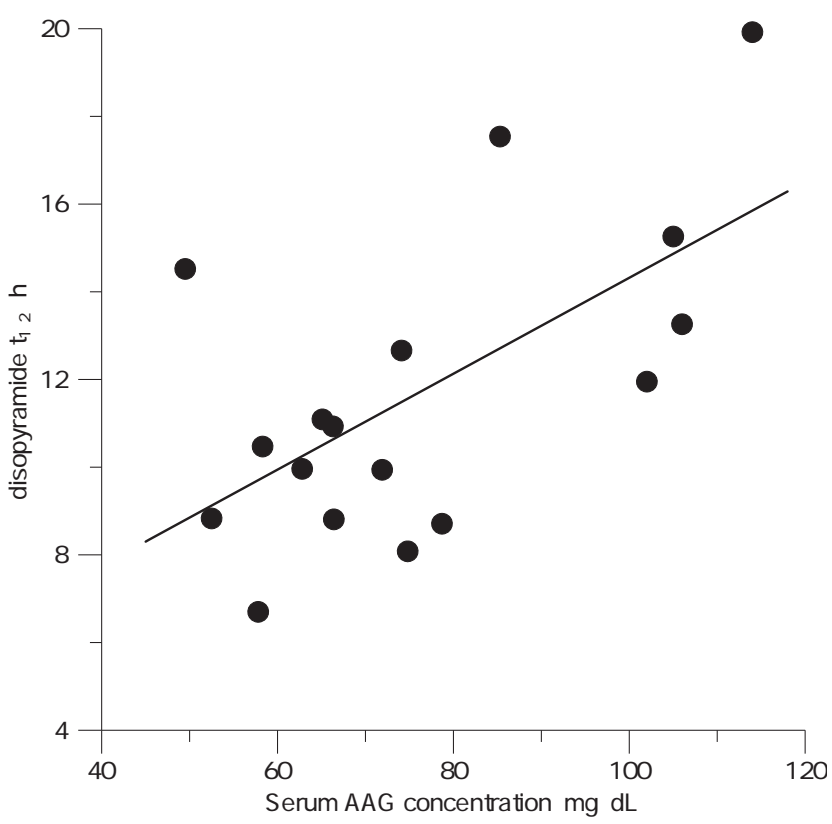

Fig. 3 Relation of the elimination half-life of disopyramide and the serum concentration of alpha- 1 acid glycoprotein $(\mathrm{AAG})\left(\mathrm{t}_{1 / 2}=0.109 \times \mathrm{AAG}+3.380\right.$, $\mathrm{n}=17, \mathrm{r}=0.620, \mathrm{p}=0.0080)$

cantly decreased to $98.2 \pm 8.0 \mathrm{mg} / \mathrm{dL} \quad(101.4 \pm 5.3 /$ $95.2 \pm 8.0 / 91$ and 83 [mild $(n=5) /$ moderate $(n=5) /$ severe $(\mathrm{n}=2)])$ at 1 hour, $90.7 \pm 7.4 \mathrm{mg} / \mathrm{dL}(95.8 \pm$ $4.1 / 88.8 \pm 7.2 / 87$ and 78 [mild $(\mathrm{n}=5) /$ moderate $(\mathrm{n}=$ $5) /$ severe $(\mathrm{n}=2)])$ at 2 hours, and $88.0 \pm 6.9 \mathrm{mg} / \mathrm{dL}$

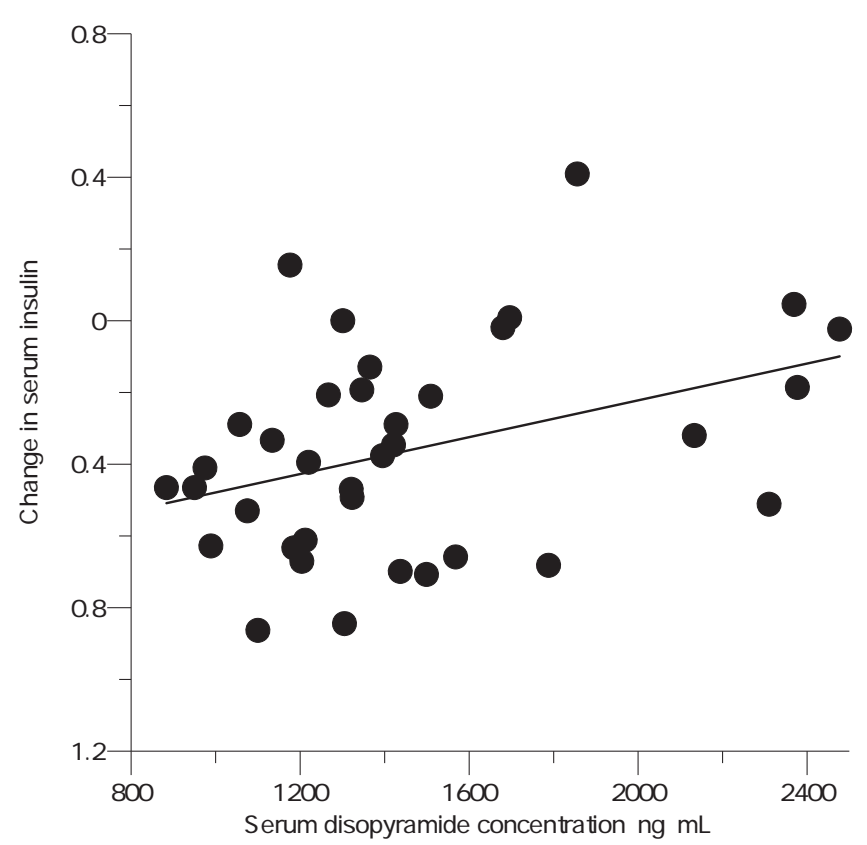

Fig. 4 Relation of the change in serum insulin level and the serum disopyramide concentration at 1,2 , and 4 hours after the disopyramide administration in the 12 subjects (change in serum insulin = $2.57 \times 10^{-4} \times$ disopyramide concentration -0.736 , $\mathrm{n}=36, \mathrm{r}=0.373, \mathrm{p}=0.0252$ )

$(90.8 \pm 3.6 / 88.0 \pm 8.5 / 86$ and $76[\operatorname{mild}(\mathrm{n}=5) / \bmod -$ erate $(n=5) /$ severe $(n=2)])$ at 4 hours after the administration $(\mathrm{p}<0.05)$. Serum insulin level before the administration was $8.2 \pm 3.1 \mu \mathrm{U} / \mathrm{mL}(8.8 \pm 2.4 /$ $8.3 \pm 4.2 / 8.3$ and 4.3 [mild $(n=5) /$ moderate $(n=$ $5) /$ severe $(n=2)])$, which also significantly decreased to $5.8 \pm 2.8 \mathrm{mg} / \mathrm{dL} \quad(5.4 \pm 2.6 / 6.5 \pm 3.6 / 6.7$ and 3.5 [mild $(n=5) /$ moderate $(n=5) /$ severe $(n=$ $2)]$ ) at 1 hour, $4.7 \pm 2.5 \mu \mathrm{U} / \mathrm{mL}(4.8 \pm 3.4 / 5.3 \pm 1.9 /$ 2.5 and 4.2 [mild $(\mathrm{n}=5) /$ moderate $(\mathrm{n}=5) /$ severe $(\mathrm{n}=2)])$ at 2 hours, and $4.6 \pm 3.4 \mu \mathrm{U} / \mathrm{mL}(6.2 \pm 4.3 /$ $3.2 \pm 2.4 / 5.9$ and 2.1 [mild $(n=5) /$ moderate $(n=$ $5) /$ severe $(n=2)])$ at 4 hours after the administration $(p<0.05)$. However, there was no significant difference between the three groups with different renal function impairment in either level. There was a weak but significant correlation was observed between serum disopyramide concentration and the change in serum insulin level (change in serum insulin $=2.57 \times 10^{-4} \times$ disopyramide concentration $0.736, \mathrm{n}=36, \mathrm{r}=0.373, \mathrm{p}=0.0252$, Fig. 4 ), but not the change in serum glucose. In contrast, no correlation was noted between monoisopropyldisopyramide and the change in either serum level of glucose or insulin. 


\section{Safety and tolerability}

No severe or serious adverse events were reported and no participant was withdrawn prematurely from the study. A total of six mild adverse events were reported by four subjects with mild or moderate renal function impairment, but none by subjects with severe renal function impairment. They were considered to be either possibly or probably related to the test medication, consisting of the drug-induced decrease in serum glucose level (from 110 to $92 \mathrm{mg}$ / dL) and caddy stool in two subjects with mild renal function impairment and the drug-induced decrease in serum glucose level (from 110 to $91 \mathrm{mg} / \mathrm{dL}$ ), caddy stool, rash and pruritus in two subjects with moderate renal function impairment. There was no trend towards clinically significant changes in 12-lead ECG recording during the trial, and in physical examination, vital signs, and laboratory parameters between pre-trial and post-trial screening.

\section{Discussion}

We studied the effect of renal function impairment on the pharmacokinetics of disopyramide and its major metabolite after the single administration of disopyramide, and demonstrated that disopyramide pharmacokinetics might be affected by serum concentration of AAG as well as renal function impairment in Japanese subjects. As reported in previous studies in Caucasian population ${ }^{2,3)}$, renal function impairment affected the pharmacokinetics of disopyramide and its metabolite, monoisopropyl disopyramide. In our present study, mean $\mathrm{CL} / \mathrm{F}$ and $\mathrm{t}_{1 / 2}$ of disopyramide varied from $5263 \mathrm{~mL} / \mathrm{h}$ and 9.95 hours in mild renal function impairment to $3428 \mathrm{~mL} / \mathrm{h}$ and $14.47 \mathrm{~h}$ in severe renal function impairment, respectively, and in healthy 12 Japanese subjects mean CL/F and $t_{1 / 2}$ were reported to be $6173 \mathrm{~mL} / \mathrm{h}$ and $6.05 \mathrm{~h}$, respectively ${ }^{12}$. These results were in line with the study reported by Francois et $\mathrm{al}^{2)}$. Since disopyramide $\mathrm{C}_{\max }$ was not affected, renal function impairment would affect disopyramide elimination from the body but not its absorption.

Interestingly, the disopyramide pharmacokinetics is affected not only by renal function impairment, but also by serum AAG concentration, an acute phase protein $^{13,14)}$, because there was a significant correlation between its serum level and disopyramide $t_{1 / 2}$, AUC, $\mathrm{CL} / \mathrm{F}$, and $\mathrm{V} / \mathrm{F}$ in the present study. The bound fraction of disopyramide at 3 and 12 hours after the administration were around $70 \%$, suggesting specific binding site for disopyramide in AAG. Disopyramide binding to serum AAG was reported to be concentration-dependent and saturable in the therapeutic range of its plasma concentrations ${ }^{15}$. Therefore, the unbound fraction of disopyramide should be increased dramatically when total disopyramide concentration rises and the binding site is saturated. Although the unbound fraction was measured at only two points in the present study, the unbound fraction would be much valuable in evaluating disopyramide pharmacokinetics and pharmacodynamics. The binding parameters of disopyramide were 0.24 and 0.838 $\mu \mathrm{M}$ for $\mathrm{Nb}$ and $\mathrm{Kd}$, respectively, in our present findings, and similar to those $(0.23$ and $1.40 \mu \mathrm{M}$ for $\mathrm{Nb}$ and $\mathrm{Kd}$, respectively) in a previous study ${ }^{11)}$. In contrast, the bound fraction of monoisopropyldisopyramide was much less than that of disopyramide, and its specific binding to $A A G$ is unlikely. Previous studies demonstrated that serum AAG concentrations were significantly higher in hemodialyzed and uremic patients than in the control subjects ${ }^{7,8)}$. In our present study, however, the renal function impairment of the subjects were not so severe that no one was on dialysis treatment or in an uremic state, and no significant difference was noted in mean AAG concentration between the three groups with different renal function impairment. Since there was no relation between serum AAG concentration and CLcr, both of them would affect the disopyramide pharmacokinetics independently. Relatively higher bound fraction of disopyramide to AAG suggested that this protein might play a role as a reservoir of disopyramide, contributing to elongation in $t_{1 / 2}$, increase in $\mathrm{AUC}$, reduction in $\mathrm{CL} / \mathrm{F}$, and decrease in $\mathrm{V} / \mathrm{F}$ of disopyramide.

In the effect of disopyramide administration on serum level of glucose or insulin in the 12 subjects without the treatments of sulfonylurea or insulin, both serum glucose and insulin level during 4 hours after the administration of disopyramide were significantly lower than those before the administration after overnight fasting, but no significant difference was noted between the three groups with different renal function impairment. Although we could not find any sign or symptom of hypoglycemia in each subject of the present study, there was a weak but significant correlation was observed between plasma disopyramide concentration and the change in serum insulin 
level, suggesting that higher plasma disopyramide concentration might lead to smaller suppression in insulin secretion. Blocking the pancreatic ATPsensitive $\mathrm{K}$ channels by disopyramide was considered to enhance insulin secretion from the pancreas ${ }^{16)}$. In addition, the decrease in serum glucose level by disopyramide was greater in elderly or thin subjects with their body weight less than $45 \mathrm{~kg}^{6,17)}$, suggesting multiple factors would affect disopyramide-induced insulin secretion. As regard limitation of the study, our findings were obtained in a relatively smaller group of subjects after the single administration of disopyramide, and therefore further studies should be required to examine the relation between plasma disopyramide concentration and insulin level or other adverse reactions related with higher plasma concentration of the drug in larger number of subjects with repeated administration of disopyramide.

Since disopyramide pharmacokinetics was significantly affected in the group with severe renal function impairment, the dosage adjustment of disopyramide may be considered in those subjects with severe renal function impairment. The maximum concentration of disopyramide at steady state can be calculated from the accumulation index, $1 /\left(1-\exp ^{(-\mathrm{kel} \cdot \mathrm{t})}\right)$, and mean $\mathrm{C}_{\max }$ after a single dose. When $100 \mathrm{mg}$ disopyramide was administered every 8 hours, the $\mathrm{C}_{\max }$ of disopyramide at the steady state was estimated to be at around $3800 \mathrm{ng} / \mathrm{mL}, 4000 \mathrm{ng} / \mathrm{mL}$, and $5000 \mathrm{ng} / \mathrm{mL}$ for patients with mild, moderate, and severe renal function impairment, respectively. When the dosing interval was elongated to every 12 hours in patients with severe renal function impairment, the concentration decreased to around $3700 \mathrm{ng} / \mathrm{mL}$, which was closer to the levels of patients with mild and moderate renal function impairment in every 8 hours dosing of $100 \mathrm{mg}$ disopyramide. Similar estimation was obtained in monoisopropyldisopyramide, which has anticholinergic effect as well, and a patient with severe renal function impairment, whose CLcr level calculated by the Cockcroft-Gault method ranges from 10 $\mathrm{mL} / \mathrm{min}$ to $30 \mathrm{~mL} / \mathrm{min}$, may be recommended the reduction in dosing rate of $100 \mathrm{mg}$ disopyramide from three times per day to twice per day. In addition to severe renal function impairment, higher serum AAG concentration may be a risk factor of that elevates plasma disopyramide concentration and induces toxic effects because serum AAG concentration was significantly correlated with disopyramide pharmaco- kinetics in our present study. Further studies should be required to evaluate whether serum AAG concentration affect disopyramide pharmacokinetics and the adjustment of disopyramide dosage would be necessary in a patient who has both conditions of higher serum AAG concentration and severe renal function impairment.

\section{References}

1) Miller JM, Zipes DP. Therapy for Cardiac Arrhythmias. Braunwald's Heart Disease: A textbook of cardiovascular medicine, 7th ed. Zipes DP, Libby P, Bonow RO, Braunwald E (Eds). Elsevier Saunders Philadelphia, 2005 : 713-66.

2) Francois B, Mallein R, Rondelet J, Lussignol M. Pharmacokinetics of disopyramide in patients with chronic renal failure. Eur J Drug Metab Pharmacokinet. $1983 ; 8: 85-92$.

3) Johnston A, Henry JA, Warrington SJ, Hamer NA. Pharmacokinetics of oral disopyramide phosphate in patients with renal impairment. Br J Clin Pharmacol. $1980 ; 10: 245-8$.

4) Goldberg IJ, Brown LK, Rayfield EJ. Disopyramide (Norpace)induced hypoglycemia. Am J Med. 1980 ; 69 : 463-6.

5) Quevedo SF, Krauss DS, Chazan JA, Crisafulli FS, Kahn CB. Fasting hypoglycemia secondary to disopyramide therapy. Report of two cases. JAMA. $1981 ; 245: 2424$.

6) Cacoub P, Deray G, Baumelou A, Grimaldi A, Soubrie C, Jacobs C. Disopyramide-induced hypoglycemia : case report and review of the literature. Fundam Clin Pharmacol. $1989 ; 3$ : 527-35.

7) Pedersen LE, Bonde J, Graudal NA, Backer NV, Hansen JE, Kampmann JP. Quantitative and qualitative binding characteristics of disopyramide in serum from patients with decreased renal and hepatic function. Br J Clin Pharmacol. 1987 ; 23 : 41-6.

8) Vasson MP, Paul JL, Couderc R, Albuisson E, Bargnoux PJ, Baguet JC, et al. Serum alpha-1 acid glycoprotein in chronic renal failure and hemodialysis. Int J Artif Organs. 1991 ; 14 : 92-6.

9) Cockcroft DW, Gault MH. Prediction of creatinine clearance from serum creatinine. Nephron. $1976 ; 16: 31-41$.

10) O'Rourke ST. Antianginal actions of beta-adrenoceptor antagonists. Am J Pharm Educ. $2007 ; 71: 95$.

11) Kishino S, Nomura A, Di ZS, Sugawara M, Iseki K, Kakinoki S, et al. Changes in the binding capacity of alpha-1-acid glycoprotein in patients with renal insufficiency. Ther Drug Monit. $1995 ; 17$ : 449-53.

12) Kato K, Tateno M, Daita H, Ootuka Y, Okui K. Pharmacokinetics of $150 \mathrm{mg}$ disopyramide phosphate retard in single administration. Therapeutic Research. 1985 ; 2 : 121-9 (in Japanese).

13) Fournier T, Medjoubi-N N, Porquet D. Alpha-1-acid glycoprotein. Biochim Biophys Acta. 2000 ; 1482 (1-2) : 157-71.

14) Hochepied T, Berger FG, Baumann H, Libert C. Alpha (1)-acid glycoprotein : an acute phase protein with inflammatory and immunomodulating properties. Cytokine Growth Factor Rev. $2003 ; \mathbf{1 4}: 25-34$.

15) Siddoway LA, Woosley RL. Clinical pharmacokinetics of disopyramide. Clin Pharmacokinet. $1986 ; 11: 214-22$.

16) Hayashi S, Horie M, Tsuura $Y$, Ishida H, Okada $Y$, Seino $Y$, et al. Disopyramide blocks pancreatic ATP-sensitive $\mathrm{K}+$ channels and enhances insulin release. Am J Physiol. $1993 ; \mathbf{2 6 5}$ (2 Pt 1) : C337-42.

17) Hasegawa J, Mori A, Yamamoto R, Kinugawa T, Morisawa T, Kishimoto Y. Disopyramide decreases the fasting serum glucose level in man. Cardiovasc Drugs Ther. $1999 ; 13: 325-7$. 